\title{
Lymph Flow Dynamics into the Thoracic Duct of the Rat
}

\author{
Seiji Yamada, Masahiro Kubo, and Yoshiaki Hayashida \\ Department of Systems Physiology, University of Occupational and \\ Environmental Health, Kitakyushu, Fukuoka, 807 Japan
}

\begin{abstract}
Summary Lymph flow into the thoracic duct of rats is reduced by $60 \%$ through immobilization with anesthesia. From this reduction, changes of the autonomic nervous activity by $\alpha$-chloralose accounts for $20 \%$. Pancuronium bromide blocking of the skeletal neuromuscular junction reduces lymph flow in the anesthetized rats by an additional $4 \%$.
\end{abstract}

Key words: thoracic duct lymph, forces affecting lymph flow, rat.

Lymph flow into the thoracic duct is affected by many factors including lymph formation (YOFFEY and COURTICE, 1970), and anesthetics decrease lymph flow into the thoracic duct (SChad and Brechtelsbauer, 1977; Yamada et al., 1983). Some of the factors responsible for the decreased lymph flow into the thoracic duct during anesthesia are changes in the regional blood flow (MILLER et al., 1980) and in the lymph formation in the regional organs (YAMADA et al., 1983).

Immobilization (loss of skeletal muscle movement by anesthetics) of the animal is one of the factors that may decrease lymph flow into the thoracic duct. The lymph flow into the thoracic duct was also affected by other agents (BARROWMAN, 1978; OHHASH et al., 1978). No reports have been written on the quantitative measurement of the factors affecting lymph flow into the thoracic duct. In this study, thoracic duct lymph flow was examined both in awake rats and rats anesthetized with a variety of agents to demonstrate the effect both of the loss of skeletal muscle movement by anesthesia and of the autonomic nervous activity on lymph flow. Finally, the effect of pancuronium bromide blocking of the skeletal neuromuscular junction was studied.

Surgical procedure. Wistar strain rats weighing $200-600 \mathrm{~g}(N=60)$ were used. Rats were starved for $24 \mathrm{~h}$ but given water ad libitum. Surgical procedures were the same as reported previously (YAMADA et al., 1983, 1984). In brief, the abdomen in the anesthetized rat was opened through a transverse left subcostal incision. After splenectomy, visceral organs were retracted with moist gauze to create the

Received for publication June 7, 1988 
operative field. The exposed thoracic duct behind the abdominal aorta was cannulated with a silicon tube (SH-OO, Dow Corning, $1.0 \mathrm{~mm}$ o.d.) below the diaphragm. The tube was exteriorized through the main incision. A tracheal catheter was used to avoid respiratory obstruction during anesthesia.

Awake rats were restricted in a modified Bollman cage, and given water ad libitum for 1 day of recovery after surgery.

Measurement. Lymph flow $(\mu \mathrm{l} / \mathrm{min} 100 \mathrm{~g}$ of body weight) into the thoracic duct was determined every $15 \mathrm{~min}$ for $6 \mathrm{~h}$ by the collection of lymph in a microtest tube (Eppendorf, Brinkman, Westbury, NY) and by measuring the weight of the microtest tube. The results which were obtained between $1-5 \mathrm{~h}$ were used for the analysis. Protein concentration of lymph was measured with a refractometer calibrated by the micro Kjeldahl method (YAmada et al., 1983). The amount of protein transported into the thoracic duct was calculated from the product of lymph flow and lymph protein concentration.

General protocol. Several anesthetic agents were used. $\alpha$-Chloralose (10 mg/100 g of body weight) was administered intraperitoneally. Sodium thiopental $(5 \mathrm{mg} / 100 \mathrm{~g}$ of body weight) was initially injected intraperitoneally, with anesthesia maintained by intravenous injection $(1.5 \mathrm{mg} / 100 \mathrm{~g}$ of body weight) every $1 \mathrm{~h}$. Urethane $(0.25 \mathrm{~g} / 100 \mathrm{~g}$ of body weight $)$ was injected subcutaneously. Two \% halothane in air was used to maintain anesthesia with a respirator (OS-R, Otani Co., Kyoto) using a constant volume $(5 \mathrm{ml} /$ stroke) at 60 times $/ \mathrm{min}$. Pancuronium bromide $(5 \mu \mathrm{g} / 100 \mathrm{~g}$ of body weight, TAYLOR, 1985) was injected intravenously every 30 min to block the skeletal neuromuscular juniction, and breathing was maintained by a respirator.

Statistics. The results were analyzed with the Student $t$-test and the null hypothesis was rejected when $p<0.05$.

Table 1. Comparison of lymph flow, lymph protein concentration, and protein amount transported into the thoracic duct under various conditions.

\begin{tabular}{lcccc}
\hline & $n$ & $\begin{array}{c}\text { Lymph flow } \\
(\mu \mathrm{l} / \mathrm{min} 100 \mathrm{~g} \text { b.w. })\end{array}$ & $\begin{array}{c}\text { Lymph protein } \\
\text { concentration } \\
(\mu \mathrm{g} / \mu \mathrm{l})\end{array}$ & $\begin{array}{c}\text { Lymph protein amount } \\
\text { into the thoracic duct } \\
(\mu \mathrm{g} / \mathrm{min} 100 \mathrm{~g} \text { b.w. })\end{array}$ \\
\hline Awake & 47 & $4.0 \pm 2.0^{*}$ & $29.4 \pm 4.9$ & $114.5 \pm 51.3^{*}$ \\
Chloralose & 36 & $2.4 \pm 1.2^{* *}$ & $24.3 \pm 6.4$ & $53.1 \pm 16.7$ \\
Thiopental & 18 & $1.7 \pm 0.4$ & $31.2 \pm 3.4$ & $51.4 \pm 21.6$ \\
Ether & 26 & $1.8 \pm 0.5$ & $30.6 \pm 3.4$ & $53.3 \pm 17.1$ \\
Urethane & 17 & $1.5 \pm 0.5$ & $31.1 \pm 2.9$ & $44.7 \pm 14.6$ \\
Halothane & 21 & $1.5 \pm 0.2$ & $28.0 \pm 2.2$ & $40.4 \pm 7.2$ \\
\hline
\end{tabular}

Values are mean \pm S.D. ${ }^{*}$ Means that the value is significantly $(p<0.01)$ higher than those of other groups. ${ }^{* *}$ Means that the value is significantly $(p<0.02)$ higher than those under other anesthetic conditions. 
Table 2. Effect of blocking of skeletal neuromuscular junction by pancuronium bromide on lymph flow, lymph protein concentration, and protein amount transported into the thoracic duct under anesthetic conditions.

\begin{tabular}{lcccc}
\hline & P.B. $n$ & $\begin{array}{c}\text { Lymph flow } \\
(\mu \mathrm{l} / \mathrm{min} 100 \mathrm{~g} \text { b.w. })\end{array}$ & $\begin{array}{c}\text { Lymph protein } \\
\text { concentration } \\
(\mu \mathrm{g} / \mu \mathrm{l})\end{array}$ & $\begin{array}{c}\text { Lymph protein amount } \\
\text { into the thoracic duct } \\
(\mu \mathrm{g} / \mathrm{min} 100 \mathrm{~g} \mathrm{~b} . \mathrm{w} .)\end{array}$ \\
\hline \multirow{2}{*}{ Ether } & -34 & $1.8 \pm 0.6$ & $30.9 \pm 2.1$ & $55.4 \pm 17.3$ \\
& +17 & $1.5 \pm 0.7$ & $29.1 \pm 3.4$ & $43.3 \pm 19.2^{*}$ \\
\hline \multirow{3}{*}{ Thiopental } & -18 & $1.7 \pm 0.7$ & $32.5 \pm 3.6$ & $51.8 \pm 25.4$ \\
& +12 & $1.4 \pm 0.7$ & $28.2 \pm 3.5$ & $36.1 \pm 13.5^{*}$ \\
\hline
\end{tabular}

Values are mean \pm S.D.; P.B., pancuronium bromide. ${ }^{*}$ Means that the value is significantly $(p<0.05)$ lower than that under the control anesthetic conditions.

Lymph flow in awake rats varied widely, as can be seen in the standard deviations in Table 1. This is attributed to differences in muscular movement among animals (YAMADA et al., 1983). Lymph protein concentration and the protein amount transported into the thoracic duct that were observed under the various conditions are also summarized in Table 1 . The mean value of lymph flow in the awake rats was $4.0 \pm 2.0 \mu \mathrm{l} / \mathrm{min}$ of $100 \mathrm{~g}$ of body weight, and was significantly $(p<0.01)$ reduced to $40 \%$ by anesthesia $(1.6 \pm 0.6 \mu \mathrm{l} / \mathrm{min}$ of $100 \mathrm{~g}$ of body weight $)$. Lymph flow into the thoracic duct in the group anesthetized by $\alpha$-chloralose $(2.4 \pm 1.2 \mu \mathrm{l} / \mathrm{min}$ of $100 \mathrm{~g}$ of body weight) was reduced to $60 \%$, which was higher $(p<0.02)$ than the average flow under anesthesia produced by other anesthetic agents. No significant difference in lymph flow was found among the other anesthetics. Lymph flow into the thoracic duct in animals in which the skeletal neuromuscular junction was blocked by pancuronium bromide under either ether $(1.5 \pm 0.7 \mu \mathrm{l} / \mathrm{min} 100 \mathrm{~g}$ of body weight) or thiopental anesthesia $(1.4 \pm 0.7 \mu \mathrm{l} / \mathrm{min}$ $100 \mathrm{~g}$ of body weight) was reduced 17 and $19 \%$, respectively, more than the lymph flow reduction in the animals anesthetized without pancuronium bromide blocking $(1.8 \pm 0.6$ and $1.7 \pm 0.7 \mu \mathrm{l} / \mathrm{min} 100 \mathrm{~g}$ of body weight, respectively) (Table 2$)$.

Lymph protein concentration in the awake rats was $29.4 \pm 4.9 \mu \mathrm{g} / \mu \mathrm{l}$. Lymph protein concentration under anesthetic conditions was slightly increased, but not statistically significant. Lymph protein concentration in the rats anesthetized by $\alpha$ chloralose was less $(24.3 \pm 6.4 \mu \mathrm{g} / \mu \mathrm{l})$ than in animals anesthetized with other agents.

The protein amount transported into the thoracic duct under the awake conditions $(114.5 \pm 51.3 \mu \mathrm{g} / \mathrm{min} 100 \mathrm{~g}$ of body weight) was significantly higher $(p<0.01)$ than the level in anesthetized animals. No significant difference in the amount of protein transported into the thoracic duct was found among anesthetized animals. In the chloralose-anesthetized group, the higher lymph flow and the low concentration of lymph protein yielded a similar amount of protein flow as in 
animals anesthetized with other agents.

Immobilization by anesthesia reduced lymph flow into the thoracic duct by $60 \%$ : the contribution of the autonomic nervous system activity to lymph flow measured under chloralose anesthesia can be estimated as $18 \%$. The additional $4 \%$ decrease in the lymph flow observed by blocking the skeletal neuromuscular junction demonstrates that the muscle pump is not completely blocked during anesthesia and that the muscle pump is a significant contributor to lymph flow because of the reduction of lymph flow by immobilization. Skeletal muscle activity in awake animals is the most significant factor determined lymph flow into the thoracic duct.

Significant increase in lymph flow and decrease in lymph protein concentration in animals anesthetized with chloralose, when compared to the results with other anesthetic agents, are in accord with earlier findings that lymph flow from the muscle is increased while lymph flow from visceral organs is decreased (YAMADA et al., 1983). As $\alpha$-chloralose increases the renal sympathetic activity and does not alter the blood pressure (SCHAD and SELLER, 1975), a redistribution of blood flow occurs: renal flow decreases and iliac flow increases (MANCIA and ZANCHETTI, 1981). Thus, the significant differences in lymph flow and lymph protein concentration between chloralose and other anesthetic agents can be attributed to the altered blood flow distribution mediated by the autonomic nervous system.

The protein amount transported into the thoracic duct depends almost entirely on the rate of lymph flow. Differences in lymph protein concentration under various conditions, although in some instances of statistical significance, are small. Therefore, the protein transported from the extravascular space to the vascular space through the thoracic duct is also primarily a function of the skeletal muscle activity.

In summary, lymph flow into the thoracic duct is affected by many factors. Immobilization by anesthesia reduces lymph flow by $60 \%$, activation of the autonomic nervous systems by $\alpha$-chloralose increases lymph flow by $20 \%$, and blocking of the neuromuscular junction reduces lymph flow by an additional $4 \%$.

We thank Professors N.C. Staub, J. LaDou, and T. Morimoto for critical discussion and manuscript revision. This study was supported in part by a Grant-in-Aid for Scientific Research from the Ministry of Education, Science and Culture, Japan.

\section{REFERENCES}

Barrowman, J. A. (1978) Physiology of the Gastro-intestinal Lymphatic System, Cambridge University Press, London, pp. 68-76.

Mancia, G. and ZanchetTI, A. (1981) Hypothalamic control of autonomic functions. In: Behavioral Studies of the Hypothalamus, Handbook of the Hypothalamus, ed. by Morgane, P. J. and Panksepp, J., Marcel Dekker, Inc., New York, pp. 147-202.

Miller, E. D., Kistner, J. R., and Epstein, R. M. (1980) Whole-body distribution of radioactivity labelled microspheres in the rat during anesthesia with halothane, en- 
flurane, or ketamine. Anesthesiology, 52: 296-302.

OhHashi, T., KawaI, Y., and Azuma, T. (1978) The response of lymphatic smooth muscles to vasoactive substance. Pflügers Arch., 375: 183-188.

SCHAD, H. and SELlER, H. (1975) A method for recording autonomic nerve activity in unanesthetized, freely moving cats. Brain Res., 100: 425-430.

SChad, H. and Brechtelsbauer, H. (1977) Thoracic duct lymph flow and composition in conscious dogs and the influence of anaesthesia and passive limb movement. Pflügers Arch., 371: 25-31.

TAYLOR, P. (1985) Neuromuscular blocking agents. In: Goodman and Gilman's the Pharmacological Basis of Therapeutics, ed. by Gilman, A. G., Goodman, L. S., Rall, T. W., and Murad, F., Macmillan Publ., New York, 7th ed., pp. 222-235.

Yamada, S., Isogai, Y., Morimoto, T., Miki, K., Nose, H., and ItoH, T. (1983) Effects of anesthetics on the thoracic duct lymph with special reference to the regional lymph. $J$. Kyoto Pref. Univ. Med., 92: 373-380.

Yamada, S., Morimoto, T., Nose, H., and Ogura, K. (1984) Responses of the vascularinterstitial-lymph system to saline loading in the rat. Jpn. J. Physiol., 34: 575-586.

YoffeY, J. M. and CourTiCE, F. C. (1970) Lymphatics, Lymph and the Lymphmyeloid Complex, Academic Press, London, pp. 177-178. 